\title{
Focality of Disease Onset
}

National Cancer Institute

\section{Source}

National Cancer Institute. Focality of Disease Onset. NCI Thesaurus. Code C117885.

The number of disease loci that are seen at the beginning or early stages of that disease. 